Research Article

\title{
Zinc-Doped Boron Phosphide Nanocluster as Efficient Sensor for $\mathrm{SO}_{2}$
}

\author{
Shahid Hussain, ${ }^{1}$ Shahzad Ali Shahid Chatha, ${ }^{1}$ Abdullah Ijaz Hussain, ${ }^{1}$ Riaz Hussain, \\ Muhammad Yasir Mehboob, ${ }^{2}$ Shabbir Muhammad, ${ }^{3,4}$ Zaheer Ahmad, ${ }^{5}$ \\ and Khurshid Ayub ${ }^{6}{ }^{6}$ \\ ${ }^{1}$ Department of Applied Chemistry, Government College University, Faisalabad 38000, Pakistan \\ ${ }^{2}$ Department of Chemistry, University of Okara, Okara, Punjab, Pakistan \\ ${ }^{3}$ Department of Physics, College of Science, King Khalid University, Abha, Saudi Arabia \\ ${ }^{4}$ Research Center for Advanced Materials Science (RCAMS), King Khalid University, Abha, Saudi Arabia \\ ${ }^{5}$ Department of Chemistry, University of Wah, Wah, Pakistan \\ ${ }^{6}$ Department of Chemistry, COMSATS University, Abbottabad Campus, Abbottabad 22060, Pakistan
}

Correspondence should be addressed to Khurshid Ayub; khurshid@cuiatd.edu.pk

Received 5 December 2019; Revised 8 January 2020; Accepted 9 January 2020; Published 23 February 2020

Academic Editor: Mohamed Azaroual

Copyright (C) 2020 Shahid Hussain et al. This is an open access article distributed under the Creative Commons Attribution License, which permits unrestricted use, distribution, and reproduction in any medium, provided the original work is properly cited.

\begin{abstract}
Adsorption of $\mathrm{SO}_{2}$ on pure $\mathrm{B}_{12} \mathrm{P}_{12}$ and $\mathrm{Zn}$-doped $\mathrm{B}_{12} \mathrm{P}_{12}$ is investigated through density functional theory methods. $\mathrm{Zn}$ adsorption on BP delivers four optimized geometries: B-Top, P-top, b64, and ring-enlarged geometry with adsorption energies of $-57.12 \mathrm{~kJ} /$ $\mathrm{mol},-14.50 \mathrm{~kJ} / \mathrm{mol},-22.94 \mathrm{~kJ} / \mathrm{mol}$, and $-14.83 \mathrm{~kJ} / \mathrm{mol}$, respectively. The adsorption energy of $\mathrm{SO}_{2}$ on pristine boron phosphide is $-14.92 \mathrm{~kJ} / \mathrm{mol}$. Interaction of $\mathrm{SO}_{2}$ with $\mathrm{Zn}$-doped boron phosphide gives four different geometries with adsorption energies of $-69.76 \mathrm{~kJ} / \mathrm{mol},-9.82 \mathrm{~kJ} / \mathrm{mol},-104.92 \mathrm{~kJ} / \mathrm{mol}$, and $-41.87 \mathrm{~kJ} / \mathrm{mol}$. Geometric parameters such as dipole moment, $Q_{\mathrm{NBO}}$, frontier molecular orbital analysis, PDOS, and global indices of reactivity are performed to visualize the changes in electronic properties of $\mathrm{B}_{12} \mathrm{P}_{12}$ after $\mathrm{Zn}$ and $\mathrm{SO}_{2}$ adsorption.
\end{abstract}

\section{Introduction}

Air pollution is a major concern in recent years, which has a severe toxicant impact on our environment and human health. It is generally a result of releasing poisonous substances such as noxious gases and very fine particles including carbon monoxide $(\mathrm{CO})$ and sulphur dioxide $\left(\mathrm{SO}_{2}\right)$ [1-3]. Sulphur dioxide is an industrial effluent and contributes to air contamination. Burning of petroleum products is also a main source of sulphur dioxide which leads to the number of breathing problems and lung and vascular diseases [4]. Lefohn and Tingey [5] studied the impacts of $\mathrm{SO}_{2}$ and $\mathrm{O}_{3}$ impact on vegetation. They analyzed air quality data to determine the co-occurrence frequency for pollutant pairs.

Due to reactive nature and significant presence of ozone and sulphur dioxide, their monitoring is highly essential.
Therefore, development of new ozone $\left(\mathrm{O}_{3}\right)$ and sulphur dioxide $\left(\mathrm{SO}_{2}\right)$ sensors have gained significant importance in scientific community. In these days, nanostructure semiconductors are of great interest due to their unique physical and chemical properties [6-8].

Recently, $(\mathrm{XY})_{n}$ nanostructures such as nanotubes, nanocages, and nanowires are of great scientific interest due to their unique electronic properties [9-13]. Fullerene-like cages $(\mathrm{XY})_{n}$ when $n=12,16,24$, and 28 are mainly interesting and attracting due to their unique properties. In recent theoretical studies on different $(\mathrm{XY})_{n}$ clusters, fullerene-like cages $(\mathrm{XY})_{12}$ were shown as most stable structures $[14,15]$. Fullerene structures of group III-V are being considered of great interest due to their significant applications in imaging material (LED's), environmental processes, and for magnetic recording [14-17]. 
Due to remarkable chemical and physical properties, $\mathrm{Al}_{12} \mathrm{~N}_{12}, \mathrm{Al}_{12} \mathrm{P}_{12}, \mathrm{~B}_{12} \mathrm{P}_{12}$, and $\mathrm{B}_{12} \mathrm{~N}_{12}$ are appealing to the scientific community [18-22]. Study on $\mathrm{B}_{12} \mathrm{~N}_{12}$ nanocage has shown that because of exceptional structural properties, $\mathrm{B}_{12} \mathrm{~N}_{12}$ has its applications in adsorption and electrical devices $[23,24] . \mathrm{Al}_{12} \mathrm{P}_{12}$ is also an important nanocluster of several theoretical studies for various applications $[25,26]$. $\mathrm{B}_{12} \mathrm{P}_{12}$ is a refractory semiconductor substance with unique properties. Many reports are available in the literature for adsorption and catalytic applications of $\mathrm{B}_{12} \mathrm{P}_{12}$ nanocages [27-31].

Several studies on different nanocages in the literature show that adsorption of metal significantly enhances the adsorption and catalytic properties [24, 32, 33]. In this regard, there are several theoretical reports describing the improved catalytic and adsorption abilities for metal-doped AlN and GaN nanocages [34-36]. Zhang et al. [37] studied the possibility of Ni-adsorbed AlN nanocage for hydrogen $\left(\mathrm{H}_{2}\right)$ storage. They found that in exposed $\mathrm{AlN}$, each $\mathrm{Al}$ atom adsorbs one hydrogen $\left(\mathrm{H}_{2}\right)$ molecule, whereas in the $\mathrm{Ni}$ adsorbed nanocage (AIN), the Ni atom is able to absorb up to three $\mathrm{H}_{2}$ molecules. Pan et al. [38] studied the effect of Sidoping on AlN films. In another study, Cui et al. [39] concluded that $\mathrm{Cr}$ atom has enough tendencies to separate to form $\mathrm{Cr}-\mathrm{N}-\mathrm{Cr}$-bonded embed clusters. Despite these advances, the potential of $\mathrm{Zn}$ group metals in the adsorption and catalytic process is not well documented. We became interested in studying the potential of $\mathrm{Zn}$-doped boron phosphide nanocages for the adsorption of $\mathrm{SO}_{2}$.

In this paper, we search all potential sites of zinc-decorated $\mathrm{B}_{12} \mathrm{P}_{12}$ nanocage. Then, the possibility of bare and $\mathrm{Zn}$ decoration on $\mathrm{B}_{12} \mathrm{P}_{12}$ nanocage for $\mathrm{SO}_{2}$ adsorption is investigated by DFT methods. We observe some considerable changes in the electronic properties of $\mathrm{B}_{12} \mathrm{P}_{12}$ nanocage by zinc $(\mathrm{Zn})$ doping. To our knowledge, such theoretical studies have not been reported so far in literature where adsorption of sulphur dioxide (SO2) on the surface of $\mathrm{Zn}$-decorated $\mathrm{B}_{12} \mathrm{P}_{12}$ is studied. We report the result on adsorption through binding energy values, the net charge transfer, and HOMO-LUMO distribution on all possible forms of $\mathrm{B}_{12} \mathrm{P}_{12}$ nanocages.

\section{Computational Methods}

All calculations in this study are performed at B3LYP/6-31G (d, p) level of theory by using Gaussian 09 [40]. Geometry optimization, adsorption energies, dipole moment, charge transfer $\left(Q_{\mathrm{NBO}}\right)$, the MEP (molecular electrostatic potential), frontier molecular orbitals analysis (HOMO-LUMO distribution), and PDOS (Partial density of states) are calculated to study the interaction mechanism. B3LYP/6-31G (d, p) is a reliable level of theory which is frequently used for nanoclusters [6, 23]. Many different possible orientations of zinc on BP nanocage $\left(M @ b_{66}, M @ b_{64}, M @ R_{4}, M @ R_{6}, M @\right.$ $\mathrm{B}_{\text {top }}$, and $\mathrm{M} @ \mathrm{P}_{\text {top }}$ ) are considered for optimization, but all abovementioned input geometries converged into four optimized structures which were named as M1 (ring large, in which metal atom is inserted in the ring), M2 ( $\left.\mathrm{M} @ \mathrm{~B}_{\text {top }}\right), \mathrm{M} 3$ $\left(\mathrm{M} @ \mathrm{~B}_{64}\right)$, and $\mathrm{M} 4\left(\mathrm{M} @ \mathrm{P}_{\text {top }}\right)$.
Equation (1) is used to calculate the interaction or adsorption energy of $\mathrm{Zn}$ on the BP nanocage:

$$
E_{\mathrm{ad}}=E_{\mathrm{Zn}-\mathrm{BP}}-\left(E_{\mathrm{BP}}+E_{\mathrm{Zn}}\right)
$$

where $E_{\mathrm{Zn} \text {-BP }}$ is the energy of $\mathrm{Zn}$-doped BP nanocage, whereas $E_{\mathrm{BP}}$ and $E_{\mathrm{Zn}}$ are the energies of pure BP nanocage and $\mathrm{Zn}$ metal, respectively. Equations (2) and (3) are used to calculate the interaction or adsorption energy of $\mathrm{SO}_{2}$ with pure BP nanocage and zinc-decorated BP nanocage.

$$
\begin{gathered}
E_{\mathrm{int}(\mathrm{BP})}=E_{\mathrm{SO}_{2}-\mathrm{BP}}-\left(E_{\mathrm{BP}}+E_{\mathrm{SO}_{2}}\right), \\
E_{\mathrm{int}(\mathrm{Zn}-\mathrm{BP})}=E_{\mathrm{SO}_{2}-\mathrm{Zn}-\mathrm{BP}}-\left(E_{\mathrm{Zn}-\mathrm{BP}}+E_{\mathrm{SO}_{2}}\right) .
\end{gathered}
$$

Here, $E_{\text {int }}(\mathrm{BP})$ and $E_{\text {int }}(\mathrm{Zn}-\mathrm{BP})$ represent the interaction/ adsorption energy of sulphur dioxide with BP nanocage and $\mathrm{Zn}$-decorated $\mathrm{BP}$, respectively. $E_{\mathrm{SO}_{2}-\mathrm{BP}}$ and $E_{\mathrm{SO}_{2}-\mathrm{Zn}-\mathrm{BP}}$ represent the total electronic energies of $\mathrm{SO}_{2}$-adsorbed $\mathrm{BP}$ nanocage and $\mathrm{SO}_{2}$-adsorbed $\mathrm{Zn}$ - $\mathrm{BP}$ nanocage. $E_{\mathrm{SO}_{2}}$ stands for the total energy of the single $\mathrm{SO}_{2}$.

Parr et al. [41] in 1999 studied the chemical potential $(\mu)$, and he expressed it by the following equation:

$$
\mu=-\frac{(I+A)}{2} \text {, }
$$

where $I$ represents ionization potential which is $-E_{\mathrm{HOMO}} / \mathrm{eV}$ and $A$ stands for electron affinity which is $-E_{\mathrm{LUMO}} / \mathrm{eV}$.

Moreover, the electronic properties such as softness (S), hardness $(\eta)$, and electrophilicity $(\omega)$ can be determined by using Koopmans' theorem [42]:

$$
\begin{aligned}
& \eta=\frac{(I-A)}{2}, \\
& S=\frac{1}{2 \eta}, \\
& \omega=\frac{\mu^{2}}{2 \eta} .
\end{aligned}
$$

Partial density of states (PDOS) for all systems is generated by using MultiWFN software [43].

\section{Results and Discussion}

Optimized structure of boron phosphide at B3LYP/6-31G $(d, p)$ level of theory is shown in Figure $1 . \mathrm{B}_{12} \mathrm{P}_{12}$ consists of tetragonal and hexagonal rings which are interconnected with each other. Two types of bonds are present in $\mathrm{B}_{12} \mathrm{P}_{12}$ : (i) $\mathrm{b}_{66}$ (bond shared between two hexagonal rings) and (ii) $\mathrm{b}_{64}$ (bond shared between one hexagonal ring and tetragonal ring). The $\mathrm{B}-\mathrm{P}$ bond length in the case of $\mathrm{b}_{66}$ is $1.91 \AA$ and in the case of $b_{64}$ is $1.93 \AA$.

3.1. Adsorption Energies and Bond Lengths. First, we decorated $\mathrm{B}_{12} \mathrm{P}_{12}$ nanocage with $\mathrm{Zn}$ metal. Decoration of $\mathrm{Zn}$ on $\mathrm{B}_{12} \mathrm{P}_{12}$ was done at different positions, i.e., $\mathrm{Zn} @ \mathrm{~b}_{66}(\mathrm{Zn}$ is placed on the bond shared between two hexagonal rings), $\mathrm{Zn} @ \mathrm{~b}_{64}(\mathrm{Zn}$ is placed on the bond shared between one hexagonal and one tetragonal ring), $\mathrm{Zn} @ \mathrm{~B}_{\text {top }}(\mathrm{Zn}$ is placed 

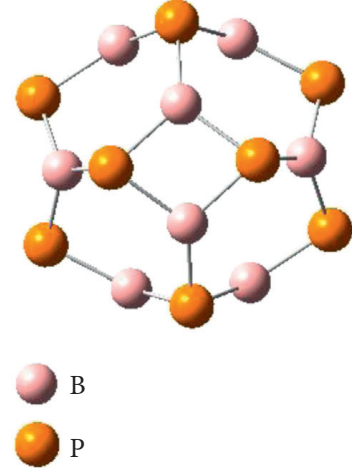

Figure 1: Optimized structure of $\mathrm{B}_{12} \mathrm{P}_{12}$ at B3LYP/6-31G (d, p) basis set.

on the top site of Boron atom), $\mathrm{Zn} @ \mathrm{P}_{\text {top }}(\mathrm{Zn}$ is placed on the top site of Phosphide atom), $\mathrm{Zn} @ \mathrm{R}_{6}(\mathrm{Zn}$ is placed on the hexagonal ring), and $\mathrm{Zn@ \textrm {R } _ { 4 }}$ ( $\mathrm{Zn}$ is placed on the tetragonal ring). With six different input geometries, only four distinct geometries could be optimized. Some of the initial input geometries converged to others during optimization. Among four distinct optimized geometries, one geometry is

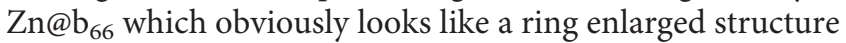
(in which $\mathrm{Zn}$ is inserted into hexagonal ring). The second

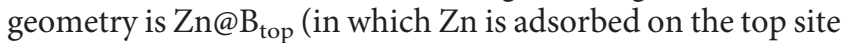

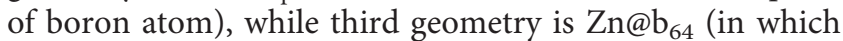
$\mathrm{Zn}$ is adsorbed on the bond shared between one hexagonal and tetragonal ring). Similarly, the fourth geometry is Zn@ $\mathrm{P}_{\text {top }}$ (in which $\mathrm{Zn}$ is adsorbed on the top of Phosphorus atom). The ring enlarged geometry, $\mathrm{Zn@b_{66 }}$ is named as M1,

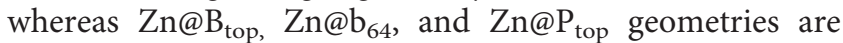
termed as M2, M3, and M4, respectively. Zn decoration on $\mathrm{B}_{12} \mathrm{P}_{12}$ (in $\mathrm{M} 1$ geometry) causes distortion in the $\mathrm{B}_{12} \mathrm{P}_{12}$ geometry, and $\mathrm{B}-\mathrm{P}$ bond lengths at the side of zinc adsorption increase to $3.98 \AA$ as compared to $1.91 \AA$ in bare $\mathrm{B}_{12} \mathrm{P}_{12}$. The adsorption energy value for $\mathrm{M} 1$ geometry is very low about $(-14.83 \mathrm{~kJ} / \mathrm{mol})$. Low adsorption energy for M1 reflects physisorption of zinc on the cage. The low interaction energy is attributed to the distortion caused by $\mathrm{Zn}$ insertion into the nanocage. No such distortion of the $\mathrm{B}_{12} \mathrm{P}_{12}$ nanocage is caused by $\mathrm{Zn}$ in $\mathrm{M} 2$ geometry which results in higher adsorption energy $(-57.12 \mathrm{~kJ} / \mathrm{mol})$. B-P bond length slightly elongated to $1.98 \AA$ as compared to $1.93 \AA$ (Figure 2). In M3 and M4 geometries, B-P bond lengths are increased slightly to $1.94 \AA$, as compared to $1.91 \AA$ in bare nanocage. This change is very small because $\mathrm{Zn}$ in both geometries does not cause any significant geometric changes (as $\mathrm{Zn}$ is adsorbed on bond shared between hexagonal and tetragonal ring and on the top of phosphorus atom). Adsorption energy values of $\mathrm{Zn}$ are $-22.94 \mathrm{~kJ} / \mathrm{mol}$ and $-14.50 \mathrm{~kJ} / \mathrm{mol}$ in $\mathrm{M} 3$ and M4, respectively.

Next, adsorption of $\mathrm{SO}_{2}$ on bare and $\mathrm{Zn}$-decorated $\mathrm{B}_{12} \mathrm{P}_{12}$ was analyzed. Here, we got one geometry in which $\mathrm{SO}_{2}$ is adsorbed on bare $\mathrm{B}_{12} \mathrm{P}_{12}$ (Figure 3 ). The value of interaction energy $(-14.92 \mathrm{~kJ} / \mathrm{mol})$ shows that $\mathrm{SO}_{2}$ is $\mathrm{fa}$ vorably adsorbed on bare $\mathrm{B}_{12} \mathrm{P}_{12}$, but through physisorption. $\mathrm{SO}_{2}$ interacts with boron phosphide nanocage through $\mathrm{O}-\mathrm{B}$ bond where oxygen of $\mathrm{SO}_{2}$ interacts with boron of the nanocage. When $\mathrm{SO}_{2}$ is adsorbed on M1, M2, M3, and M4 geometry, four geometries named as N1, N2, N3, and N4 are obtained (Figure 3 ). The values of adsorption energies in $\mathrm{N} 1, \mathrm{~N} 2, \mathrm{~N} 3$, and $\mathrm{N} 4$ are $-69.76 \mathrm{KJ} / \mathrm{mol},-9.82 \mathrm{KJ} / \mathrm{mol}$, $-104.92 \mathrm{KJ} / \mathrm{mol}$, and $-14.87 \mathrm{~kJ} / \mathrm{mol}$, respectively (Table 1 ). The distances of $\mathrm{SO}_{2}$ from $\mathrm{Zn}$ in $\mathrm{N} 1, \mathrm{~N} 2, \mathrm{~N} 3$, and $\mathrm{N} 4$ are $1.94 \AA, 2.86 \AA, 2.01 \AA$, and $2.38 \AA$, respectively. Among these geometries, N1-N3 has oxygen of $\mathrm{SO}_{2}$ coordinated to $\mathrm{Zn}$ atom, whereas $\mathrm{N} 4$ is characterized by the $\mathrm{Zn}-\mathrm{S}$ bond. The high interaction energy of $\mathrm{SO}_{2}$ adsorption on $\mathrm{Zn}$ in $\mathrm{N} 3$ is attributed to chelation of $\mathrm{SO}_{2}$ with $\mathrm{Zn}$. Interestingly, the values of adsorption energies of $\mathrm{SO}_{2}$ adsorption on bare and $\mathrm{Zn}$-doped $\mathrm{B}_{12} \mathrm{P}_{12}$ shows inverse relation with $\mathrm{Zn}$-decorated $\mathrm{B}_{12} \mathrm{P}_{12}$ except $\mathrm{N} 2$ geometry. This relation shows that $\mathrm{Zn}$ doped $\mathrm{B}_{12} \mathrm{P}_{12}$ are more stable and resists $\mathrm{SO}_{2}$ adsorption and for N2 geometry reversal is true.

3.2. Dipole Moment. Pure $\mathrm{B}_{12} \mathrm{P}_{12}$ has equal number of boron and phosphorus atoms and show zero dipole moment due to its centrosymmetric nature. Upon decoration of $\mathrm{Zn}$ on $\mathrm{B}_{12} \mathrm{P}_{12}$ nanocage ( $\mathrm{M} 1, \mathrm{M} 2, \mathrm{M} 3$, and $\left.\mathrm{M} 4\right)$, change in dipole moment is observed. Values of dipole moment for M1, M2, $\mathrm{M} 3$, and M4 geometries are $2.42 \mathrm{D}, 3.24 \mathrm{D}, 2.26 \mathrm{D}$, and $0.61 \mathrm{D}$. The highest value is counted for M2 geometry. This increase in dipole moment is due to large distance of $\mathrm{Zn}$ from $\mathrm{BP}$ cage. The vector is pointed away from $\mathrm{B}_{12} \mathrm{P}_{12}$ nanocage toward $\mathrm{Zn}$ in all geometries ( $\mathrm{Zn}$-decorated $\mathrm{BP}$ ) which is the reason of change in dipole moment after decoration of $\mathrm{Zn}$ on BP. Significant change in dipole moment is observed when $\mathrm{SO}_{2}$ is adsorbed on bare $\mathrm{B}_{12} \mathrm{P}_{12}$ (3.08 D). On interaction of $\mathrm{SO}_{2}$ with $\mathrm{N} 1, \mathrm{~N} 2, \mathrm{~N} 3$, and $\mathrm{N} 4$ geometries, the dipole moment values decrease (except N4) compared to M1-M4. Values of dipole moment for N1, N2, $\mathrm{N} 3$, and $\mathrm{N} 4$ are $1.70 \mathrm{D}, 2.25 \mathrm{D}, 0.53 \mathrm{D}$, and $5.26 \mathrm{D}$. This decrease in dipole moment is due to decrease in distance of $\mathrm{SO}_{2}$ from $\mathrm{Zn}$ and higher value of interaction energies except geometry N2 where reversal is true. Dipole moment vector is pointed away from nanocage, and it is toward $\mathrm{SO}_{2}$ in all $\mathrm{SO}_{2^{-}}$ adsorbed Zn-doped BP geometries (N1-N4).

3.3. $Q_{N B O}$. Next, $Q_{\mathrm{NBO}}$ analysis is performed to correlate the charge transfer with dipole moment. The charges of $\mathrm{Zn}$ in M1-M4 geometries are 1.004, 0.524, 0.937, and 0.081, respectively. Close analysis reveal lack of any correlation between $Q_{\mathrm{NBO}}$ and dipole moment for $\mathrm{Zn}$-doped $\mathrm{B}_{12} \mathrm{P}_{12}$. This lack of correlation in $Q_{\mathrm{NBO}}$ and dipole moment suggested that intensity of charge is not only the factor in deciding the dipole moment rather separation between charges also matters a lot, besides the geometry of the $\mathrm{Zn}$ doped complex itself. So, dipole moment is depending on intensity of charges as well as displacement between $\mathrm{Zn}$ and nanocage. $Q_{\mathrm{NBO}}$ charges on $\mathrm{SO}_{2}$ in $\mathrm{SO}_{2}$-adsorbed $\mathrm{Zn}$-doped $\mathrm{BP}$ is slightly negative which reflects that $\mathrm{SO}_{2}$ is taking charge from the $\mathrm{Zn}$-doped geometries. $\mathrm{Q}_{\mathrm{NBO}}$ charges on $\mathrm{N} 1$, $\mathrm{N} 2, \mathrm{~N} 3$, and $\mathrm{N} 4$ are $-0.163,-0.093,-0.152$, and -0.147 , respectively. This negative charge is due to generation of negative $\mathrm{SO}_{2}$ atoms (which is attached with $\mathrm{Zn}$ transition 


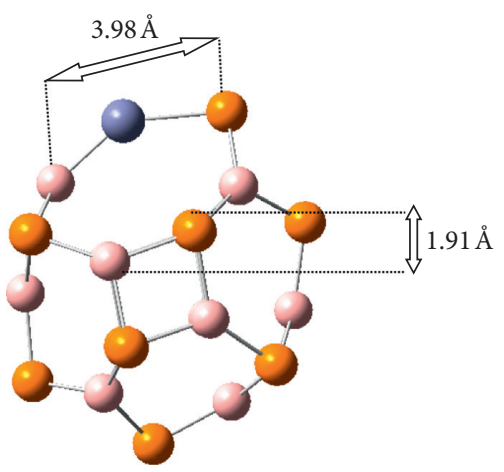

(a)

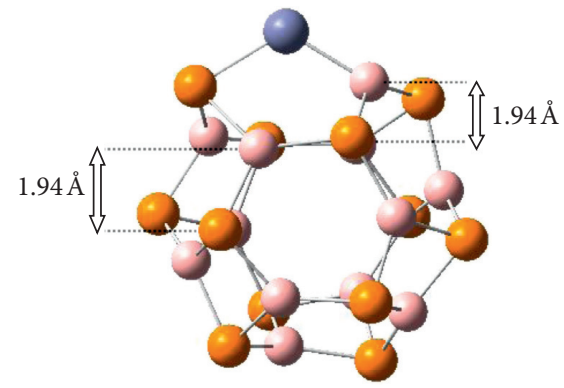

(c)

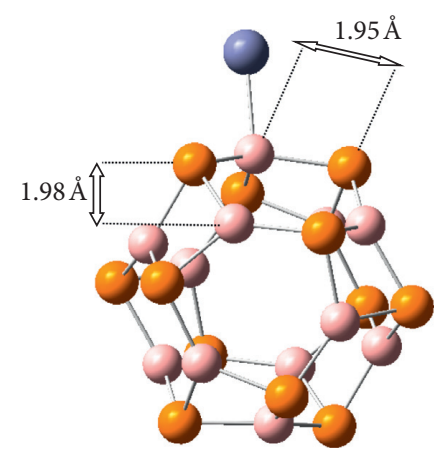

(b)

()

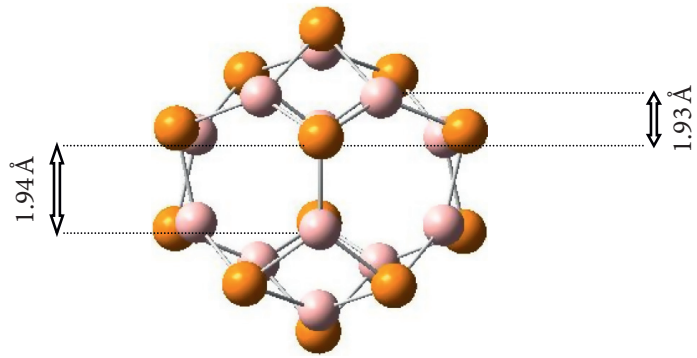

(d)

Figure 2: Optimized structures of Zn-doped $\mathrm{B}_{12} \mathrm{P}_{12}$ nanocages: (a) M1, (b) M2, (c) M3, and (d) M4.

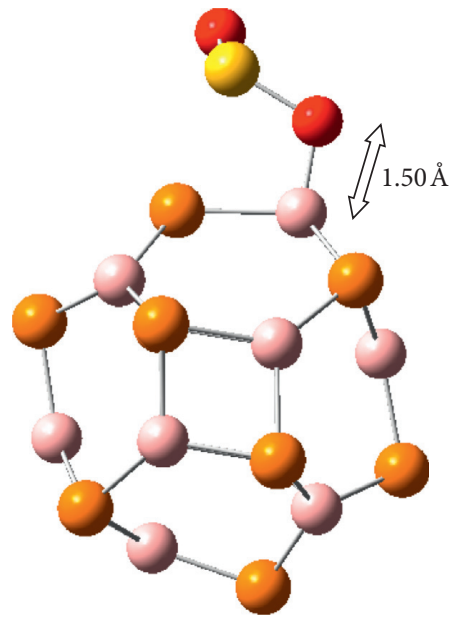

(a)

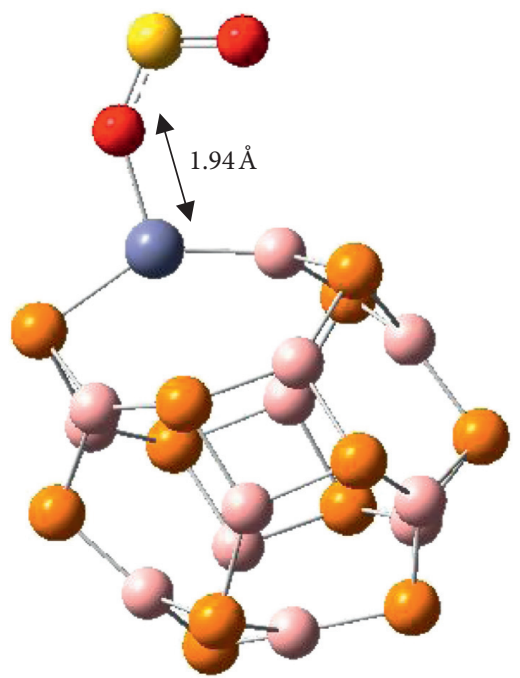

(b)

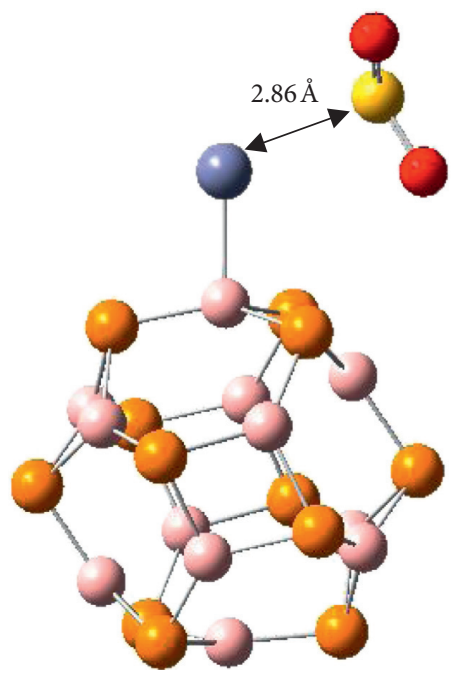

(c)

Figure 3: Continued. 


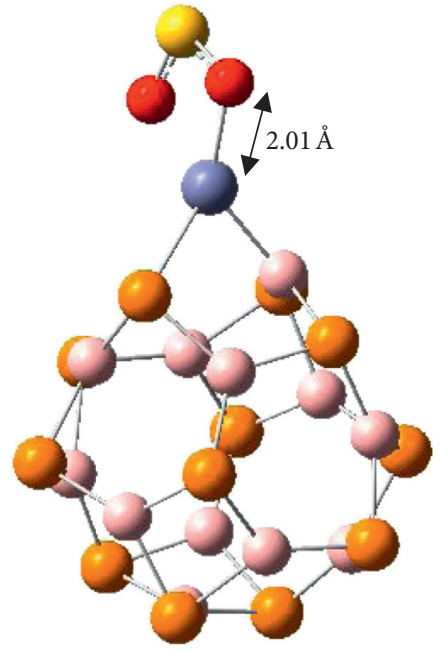

(d)

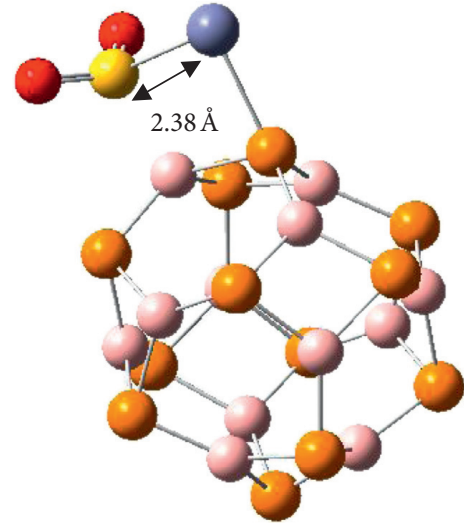

(e)

Figure 3: (a) $\mathrm{SO}_{2}$-adsorbed $\mathrm{B}_{12} \mathrm{P}_{12}$ and $\mathrm{SO}_{2}$-adsorbed Zn-doped $\mathrm{B}_{12} \mathrm{P}_{12}$ systems: (b) N1, (c) N2, (d) N3, and (e) N4.

TABLE 1: The closest distance of $\mathrm{SO}_{2}$ to $\mathrm{BP}, \mathrm{Zn}$ metal to pure $\mathrm{BP}, \mathrm{Q}_{\mathrm{NBO}}$ (Charge) on metal and gas, dipole moment, and adsorption energies of different systems.

\begin{tabular}{|c|c|c|c|c|c|c|}
\hline Systems & $d_{\mathrm{Zn}-\mathrm{BP}}(\AA)$ & $d_{\mathrm{SO}_{2}-\mathrm{Zn}}(\AA)$ & $Q_{\mathrm{NBO}}$ on $\mathrm{SO}_{2}(\mathrm{eV})$ & $Q_{\mathrm{NBO}}$ on $\mathrm{Zn}(\mathrm{eV})$ & $\mu_{\mathrm{D}}(\mathrm{D})$ & $E_{\mathrm{ad}}^{\mathrm{b}}(\mathrm{KJ} / \mathrm{mol})$ \\
\hline $\mathrm{Zn}$ & - & - & - & 0.00 & 0.00 & - \\
\hline $\mathrm{BP}$ & - & - & - & - & 0.00 & - \\
\hline $\mathrm{BP}-\mathrm{SO}_{2}$ & - & & -0.217 & - & 3.08 & -14.92 \\
\hline $\mathrm{Zn}-\mathrm{BP}(\mathrm{M} 1)$ & 2.10 & & - & 1.004 & 2.42 & -14.83 \\
\hline $\mathrm{Zn}-\mathrm{BP}-\mathrm{SO}_{2}(\mathrm{~N} 1)$ & - & $1.94^{\mathrm{a}}$ & -0.163 & - & 1.70 & -69.76 \\
\hline $\mathrm{Zn}-\mathrm{BP}(\mathrm{M} 2)$ & 2.15 & - & - & 0.524 & 3.24 & -57.12 \\
\hline $\mathrm{Zn}-\mathrm{BP}-\mathrm{SO}_{2}(\mathrm{~N} 2)$ & - & $2.86^{\mathrm{a}}$ & -0.093 & - & 2.25 & -9.82 \\
\hline $\mathrm{Zn}-\mathrm{BP}(\mathrm{M} 3)$ & 2.15 & - & - & 0.937 & 2.26 & -22.94 \\
\hline $\mathrm{Zn}-\mathrm{BP}-\mathrm{SO}_{2}(\mathrm{~N} 3)$ & - & $2.01^{\mathrm{a}}$ & -0.152 & - & 0.53 & -104.09 \\
\hline $\mathrm{Zn}-\mathrm{BP}(\mathrm{M} 4)$ & 3.00 & - & - & 0.081 & 0.61 & -14.50 \\
\hline $\mathrm{Zn}-\mathrm{BP}-\mathrm{SO}_{2}(\mathrm{~N} 4)$ & - & $2.38^{\mathrm{a}}$ & -0.147 & - & 5.26 & -41.87 \\
\hline
\end{tabular}

${ }^{\mathrm{a}}$ Metal nearest to $\mathrm{SO}_{2}$ (gas) atom towards $\mathrm{Zn}$ metal. ${ }^{\mathrm{b}}$ The calculated (adsorption) energy, which is calculated by using equations (1), (2), and (3).

metal). The trend between dipole moment and $Q_{\mathrm{NBO}}$ is true (consistent) for N1, N2, N3, and N4 (Table 1).

3.4. MEP Analysis. Next, molecular electrostatic potential (MEP) analysis is performed to unveil the change in the properties after decoration of $\mathrm{Zn}$ metal and $\mathrm{SO}_{2}$ adsorption on $\mathrm{Zn}$-doped BP as shown in Figure 4. This analysis also gives relationship between chemical reactivity and charge distribution. Yellow color shows electron-rich area (negative charge), blue color shows electron-deficient area (positive charge), and green color shows mean potential area (neutral charge). Pure $\mathrm{B}_{12} \mathrm{P}_{12}$ has equal number of boron and phosphorus atoms, so it shows no charge distribution, or in other words, it is neutral as shown in Figure 4. When $\mathrm{SO}_{2}$ is adsorbed on $\mathrm{BP}$, the yellow area is shifted on $\mathrm{SO}_{2}$ which suggested that $\mathrm{SO}_{2}$ end is an electron-rich end. But metal end shows electropositive charge (blue in color) in $\mathrm{Zn}$-doped complex, whereas the cage shows uniform charge distribution. Similarly, when $\mathrm{SO}_{2}$ is adsorbed on $\mathrm{Zn}$-decorated $\mathrm{B}_{12} \mathrm{P}_{12}$, then charge transfer towards $\mathrm{SO}_{2}$ occurs on $\mathrm{SO}_{2}$; yellow color shows negative charge end, blue color on $\mathrm{Zn}$ metal shows electropositive nature of transition metal, and cage shows equal charge distribution this trend is consistent with $Q_{\mathrm{NBO}}$.

3.5. Electronic Properties. It is seen that decoration of $\mathrm{Zn}$ on $\mathrm{B}_{12} \mathrm{P}_{12}$ and subsequent $\mathrm{SO}_{2}$ adsorption on $\mathrm{Zn}$-doped $\mathrm{B}_{12} \mathrm{P}_{12}$ brings some changes in the electronic properties of pure $\mathrm{B}_{12} \mathrm{P}_{12}$ and $\mathrm{Zn}-\mathrm{B}_{12} \mathrm{P}_{12}$. $\mathrm{Zn}$ decoration on $\mathrm{BP}$ causes narrowing of HOMO-LUMO gap which is very vital for conductivity (useful for sensing materials). The following equation shows relationship between HOMO-LUMO energy gap and conductivity [44]:

$$
\sigma \alpha \exp \left(\frac{-E g}{K T}\right)
$$

Here, “ $K$ ” represents Boltzmann's constant, and $\sigma$ represents conductivity. HOMO energies, LUMO energies, Fermi level, and HOMO-LUMO gap are calculated and given in Table 2. Fermi level makes define as the midpoint of 


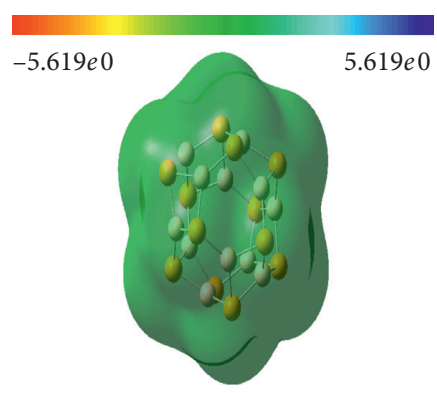

(a)

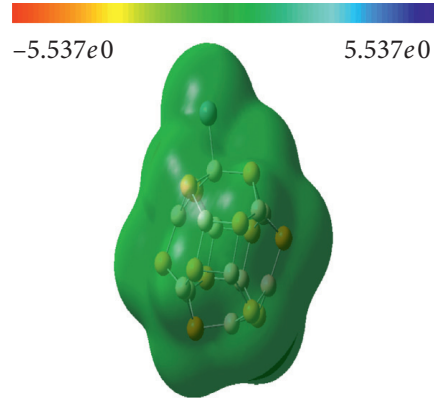

(d)

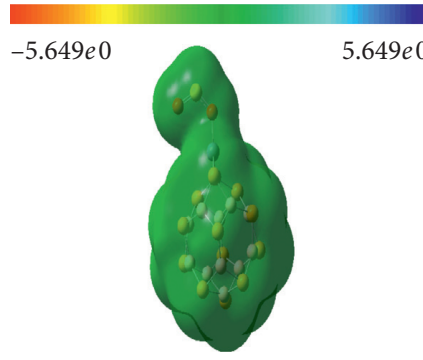

(g)

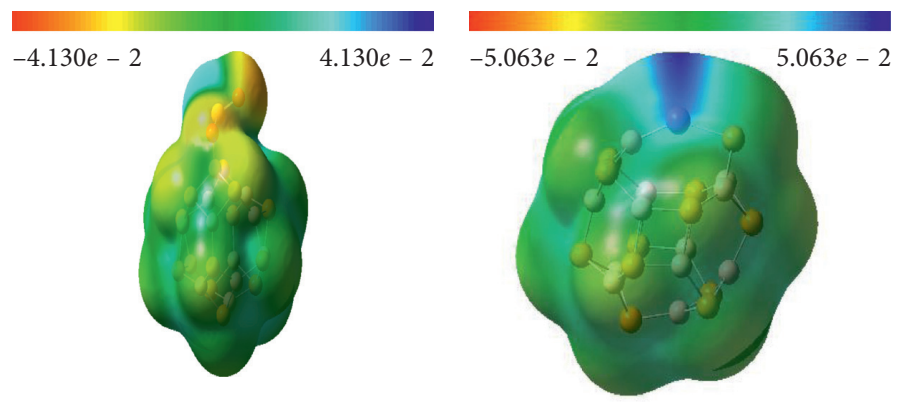

(b)

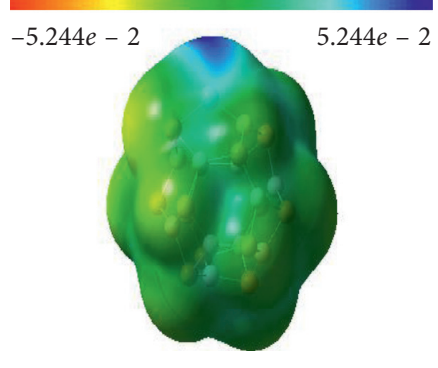

(e)

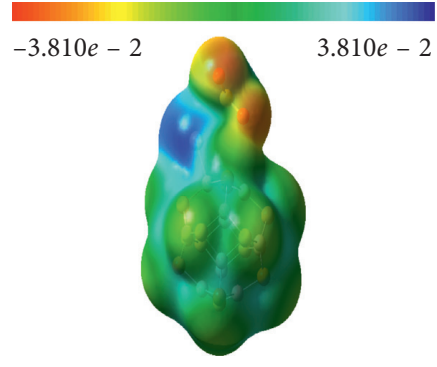

(h)

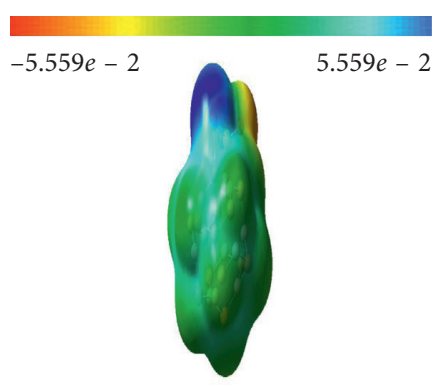

(c)

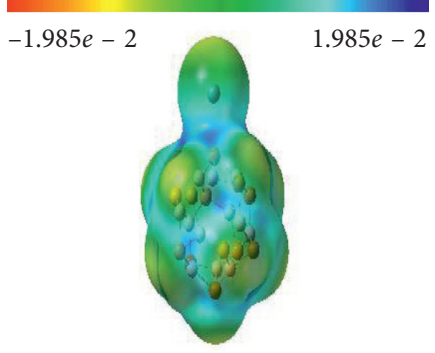

(f)

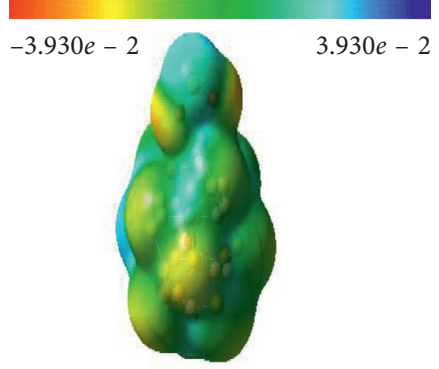

(i)

(j)

FIgURe 4: The molecular electrostatic potential map of different systems: (a) $\mathrm{B}_{12} \mathrm{P}_{12}$ nanocage, (b) $\mathrm{SO}_{2}$-adsorbed $\mathrm{B}_{12} \mathrm{P}_{12}$, (c) M1, (d) M2, (e) M3, (f) M4, (g) N1, (h) N2, (i) N3, and (j) N4.

TABle 2: The orbital parameters, HOMO-LUMO energies, fermi level, and HOMO-LUMO energy gap of different systems.

\begin{tabular}{|c|c|c|c|c|}
\hline System & $E_{\text {Номо }}(\mathrm{ev})$ & $E_{\mathrm{FL}}(\mathrm{ev})$ & $E_{\text {LUMO }}(\mathrm{ev})$ & $E_{g}(\mathrm{ev})$ \\
\hline $\mathrm{Zn}$ & -6.10 & -3.32 & -0.55 & 5.55 \\
\hline BP & -6.83 & -4.98 & -3.13 & 3.70 \\
\hline $\mathrm{BP}-\mathrm{SO}_{2}$ & -6.21 & -5.21 & -4.20 & 2.01 \\
\hline $\mathrm{Zn}-\mathrm{BP}(\mathrm{M} 1)$ & -6.33 & -4.66 & -2.99 & 3.34 \\
\hline $\mathrm{Zn}-\mathrm{BP}-\mathrm{SO} 2(\mathrm{~N} 1)$ & -5.90 & -5.32 & -4.75 & 1.15 \\
\hline $\mathrm{Zn}-\mathrm{BP}(\mathrm{M} 2)$ & -6.25 & -4.71 & -3.16 & 3.09 \\
\hline Zn-BP-SO2 (N2) & -6.35 & -5.10 & -3.84 & 2.51 \\
\hline Zn-BP (M3) & -5.92 & -4.45 & -2.99 & 2.93 \\
\hline $\mathrm{Zn}-\mathrm{BP}-\mathrm{SO}_{2}(\mathrm{~N} 3)$ & -5.47 & -4.82 & -4.18 & 1.29 \\
\hline $\mathrm{Zn}-\mathrm{BP}(\mathrm{M} 4)$ & -5.57 & -4.37 & -3.17 & 2.40 \\
\hline $\mathrm{Zn}-\mathrm{BP}-\mathrm{SO}_{2}(\mathrm{~N} 4)$ & -6.43 & -5.19 & -3.94 & 2.49 \\
\hline
\end{tabular}




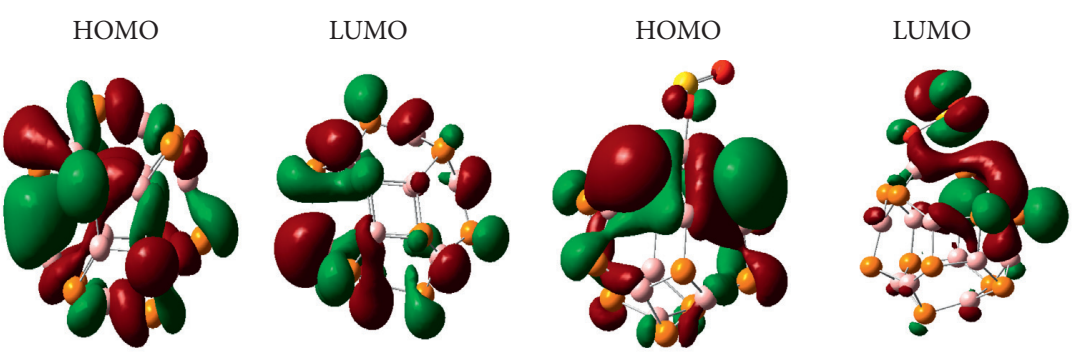

$\mathrm{B}_{12} \mathrm{P}_{12}$ nanocage

$\mathrm{B}_{12} \mathrm{P}_{12}-\mathrm{SO}_{2}$

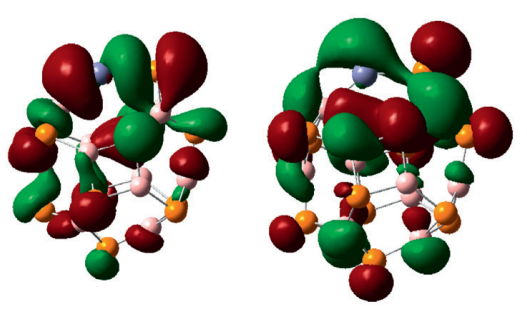

M1

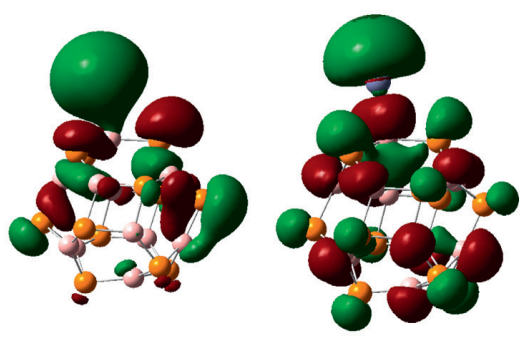

M2
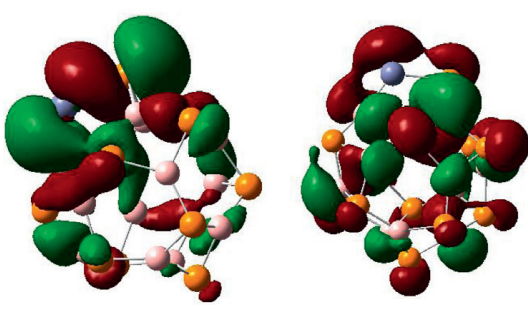

M3

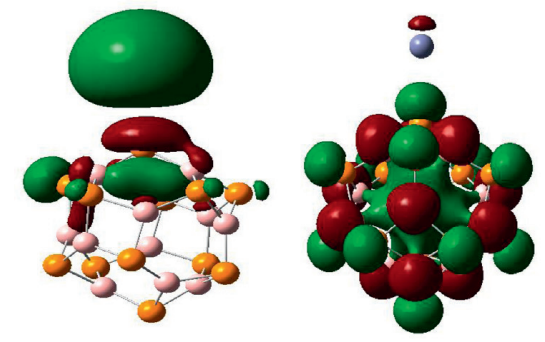

M4
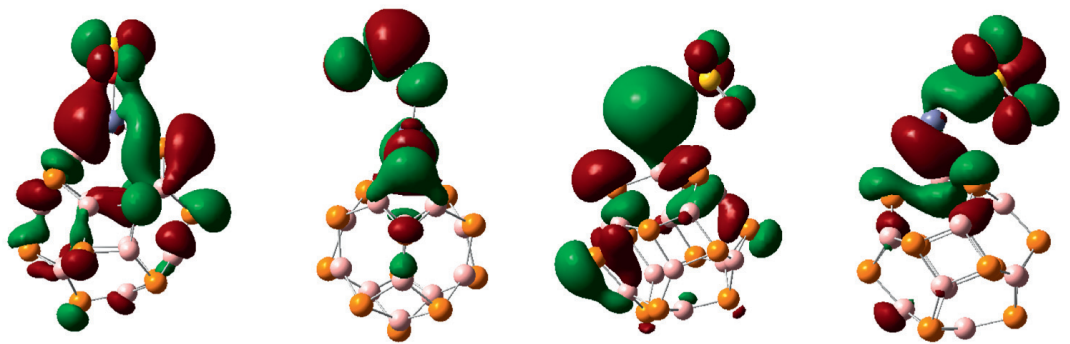

N1
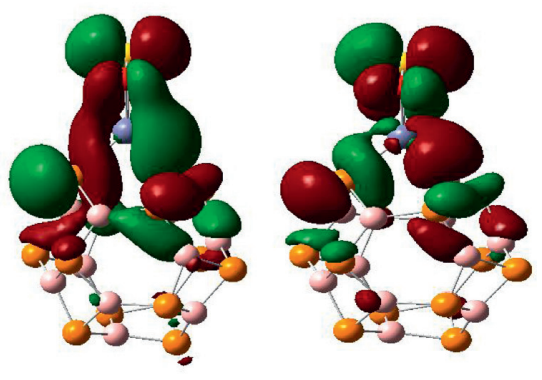

N3
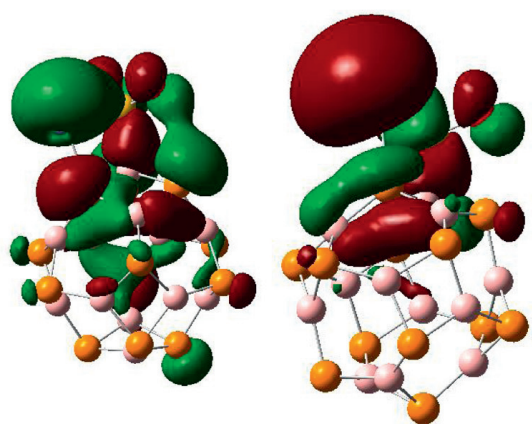

Figure 5: Side views of HOMO and LUMO of different systems. 

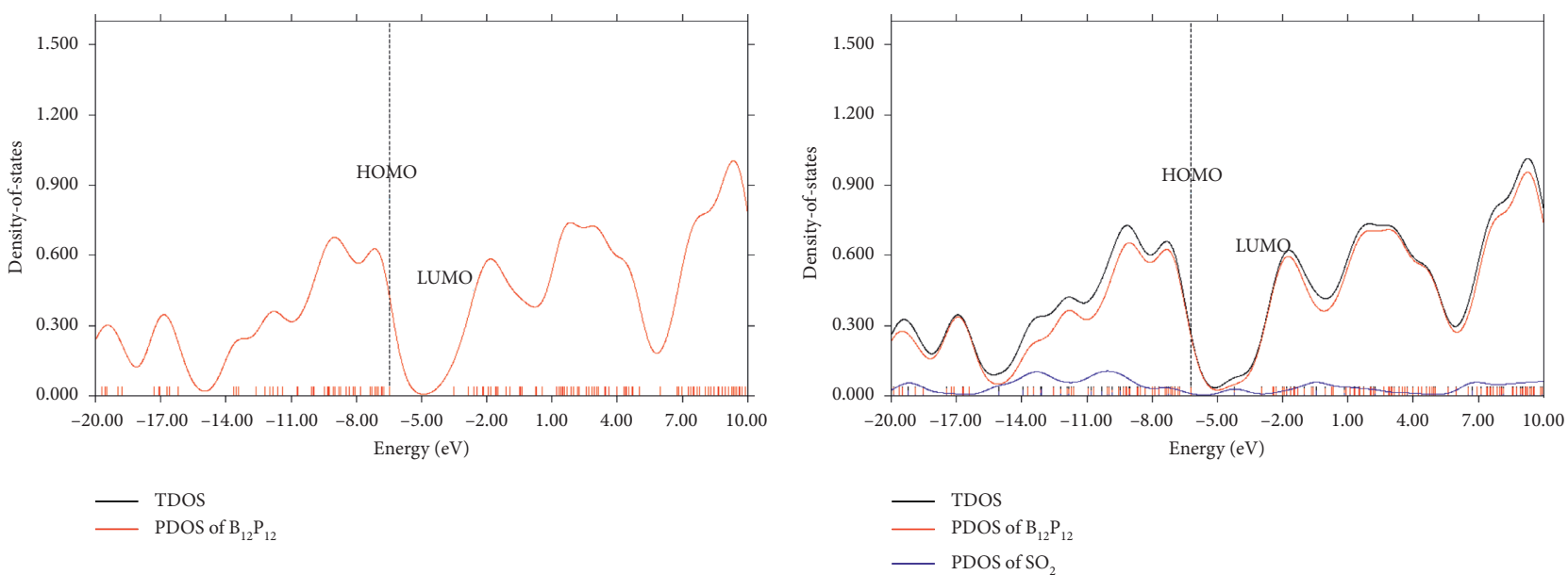

(a)

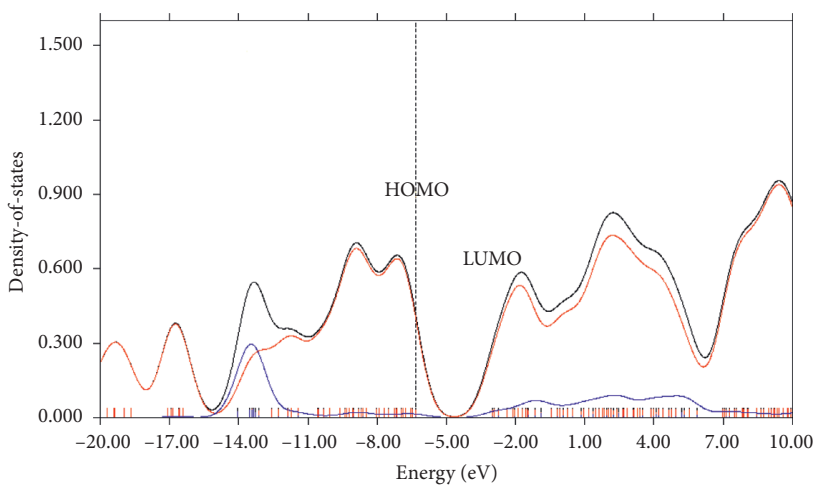

(b)

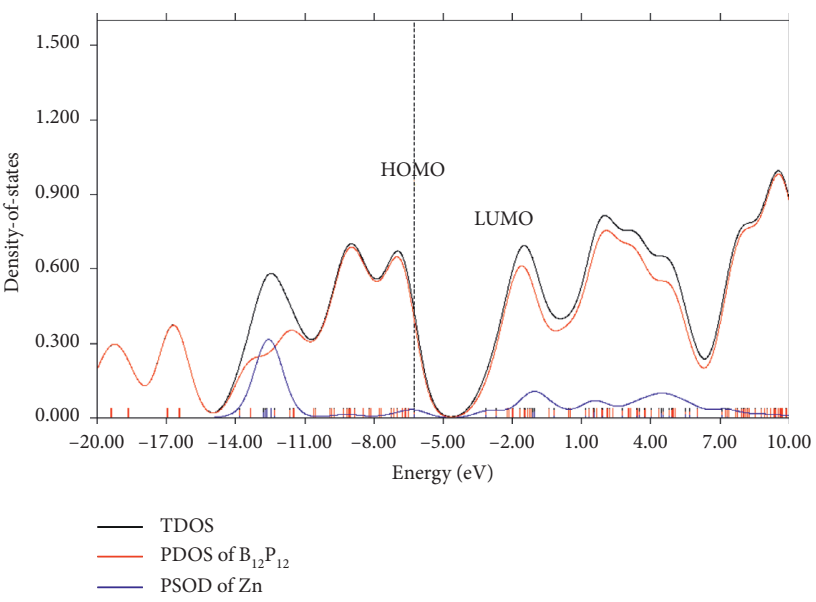

(c)

(d)
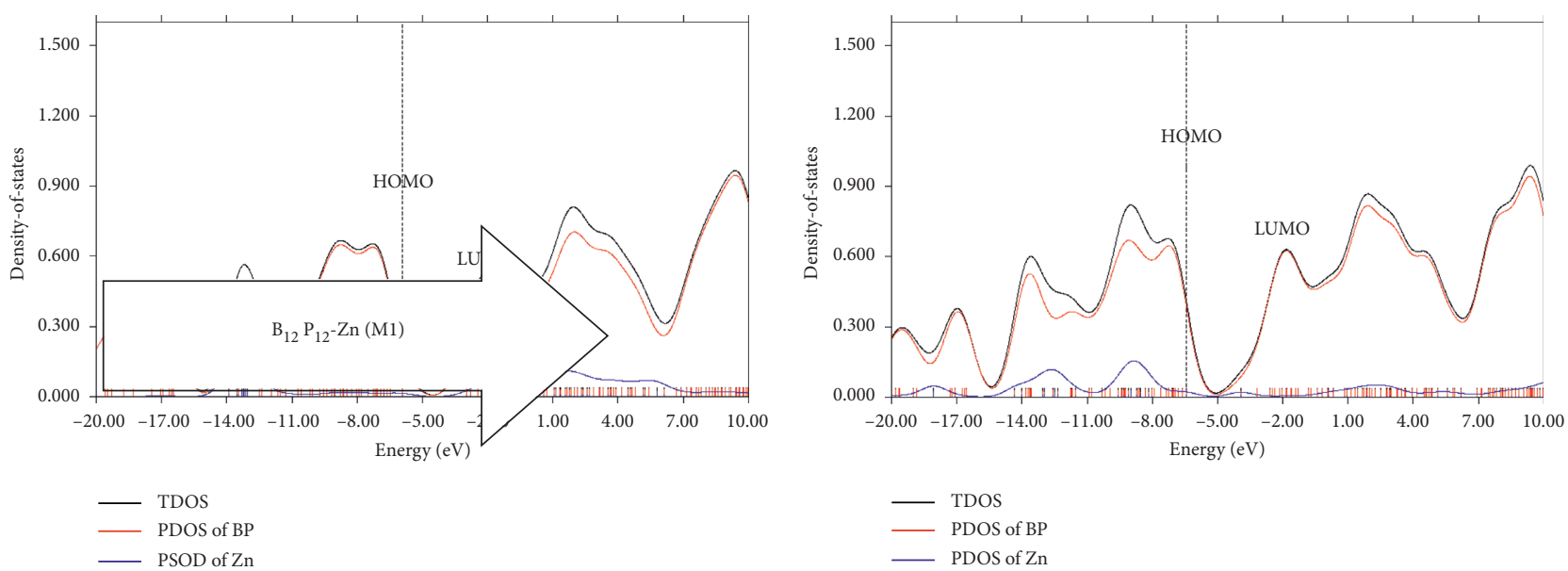

(e)

(f)

Figure 6: Continued. 


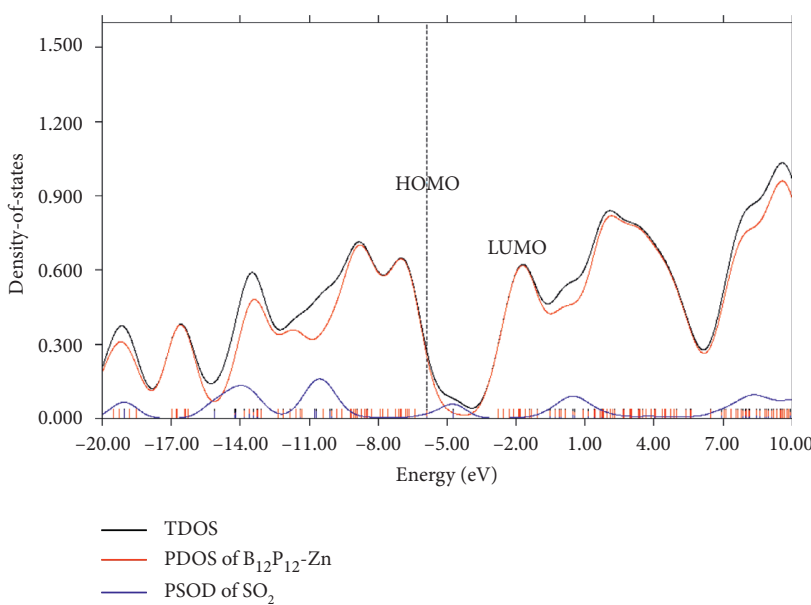

(g)

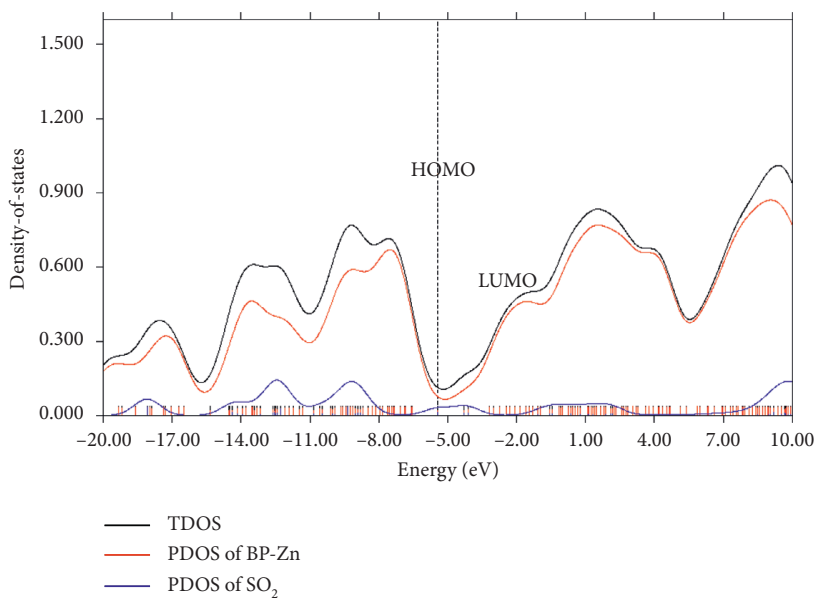

(i)

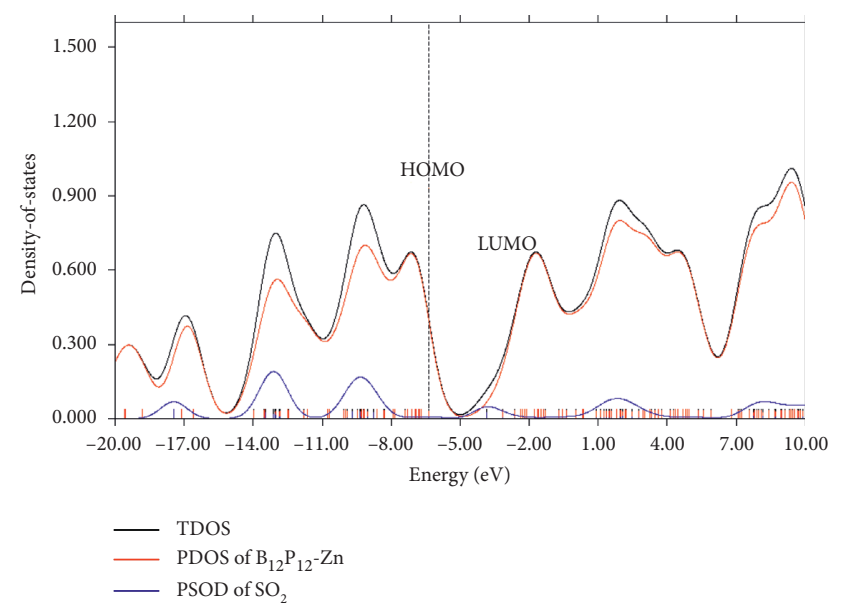

(h)

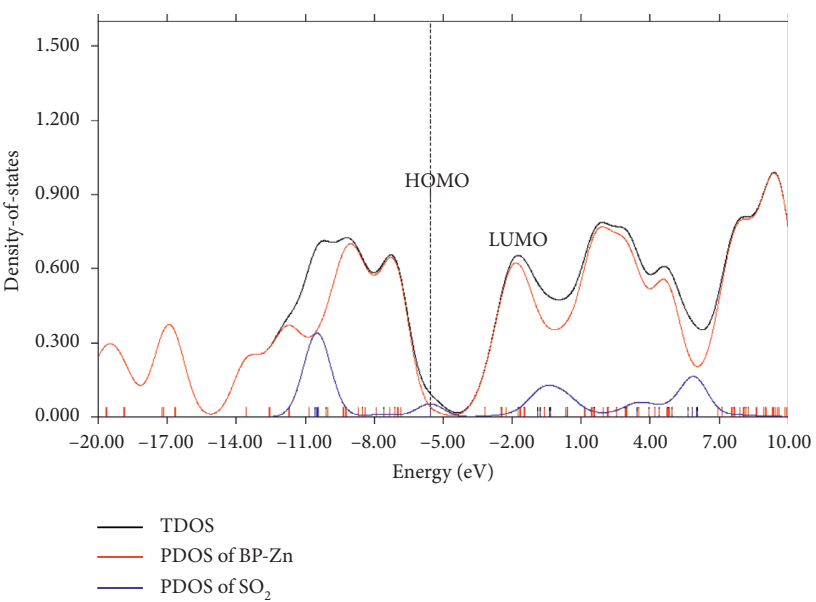

(j)

Figure 6: Different systems with TDOS and PDOS graph. The isosurfaces is $0.02 \mathrm{e} / \AA^{3}$. (a) B12P12 nanocage. (b) $\mathrm{B}_{12} \mathrm{P}_{12}-\mathrm{SO}_{2}$. (c) M1. (d) M2. (e) M3. (f) M4. (g) N1. (h) N2. (i) N3. (j) N4.

HOMO-LUMO gap in molecule at zero Kelvin temperature [45].

Pure $\mathrm{B}_{12} \mathrm{P}_{12}$ is a semiconductor with HOMO-LUMO gap of $3.70 \mathrm{eV}$. Energies of HOMO and LUMO are $-6.83 \mathrm{eV}$ and $-3.13 \mathrm{eV}$, respectively, with the Fermi level of $-4.98 \mathrm{eV}$. Upon decoration of $\mathrm{Zn}$ (transition metal) on $\mathrm{B}_{12} \mathrm{P}_{12}$ nanocage, the energies of both HOMO and LUMO increase which causes narrowing of the HOMO-LUMO gap. M1 has HOMO-LUMO gap of $3.34 \mathrm{eV}$ with the Fermi level of $-4.66 \mathrm{eV}$. Similarly, M2 has HOMO-LUMO gap of $3.09 \mathrm{eV}$ with the Fermi level of $-4.71 \mathrm{eV}$. HOMO-LUMO gaps of M3 and M4 geometries are $2.93 \mathrm{eV}$ and $2.40 \mathrm{eV}$ with the Fermi levels of $-4.45 \mathrm{eV}$ and $-4.37 \mathrm{eV}$, respectively. When $\mathrm{SO}_{2}$ is adsorbed on bare and $\mathrm{Zn}$-doped $\mathrm{B}_{12} \mathrm{P}_{12}$, then HOMOLUMO gaps become narrower as compared to $\mathrm{Zn}$-doped $\mathrm{B}_{12} \mathrm{P}_{12}$. $\mathrm{SO}_{2}$ adsorption on bare $\mathrm{B}_{12} \mathrm{P}_{12}$ causes narrowing the HOMO-LUMO to $2.01 \mathrm{eV}$ as compared to $3.70 \mathrm{eV}$ (in pure $\mathrm{B}_{12} \mathrm{P}_{12}$ ). Adsorption of $\mathrm{SO}_{2}$ on $\mathrm{Zn}$-doped $\mathrm{B}_{12} \mathrm{P}_{12}$ increase the conductivity of $\mathrm{B}_{12} \mathrm{P}_{12}$ as it causes narrowing of HOMOLUMO gap. HOMO-LUMO gap values for N1, N2, N3, and $\mathrm{N} 4$ are $1.15 \mathrm{eV}, 2.51 \mathrm{eV}, 1.29 \mathrm{eV}$, and $2.49 \mathrm{eV}$ with the Fermi level of $-5.32 \mathrm{eV},-5.10 \mathrm{eV},-4.82 \mathrm{eV}$, and $-5.19 \mathrm{eV}$, respectively (Table 2). Energies of HOMOs for N1, N2, N3, and $\mathrm{N} 4$ are $-5.90 \mathrm{eV},-6.35 \mathrm{eV},-5.47 \mathrm{eV}$, and $-6.43 \mathrm{eV}$, respectively. Similarly, LUMO energies for N1, N2, N3, and $\mathrm{N} 4$ are $-4.75 \mathrm{eV},-3.84 \mathrm{eV},-4.18 \mathrm{eV}$, and $-3.94 \mathrm{eV}$, respectively.

Moreover, frontier molecular orbital shapes also reveal significant information regarding the reactivities. When $\mathrm{B}_{12} \mathrm{P}_{12}$ is decorated with transition metal like $\mathrm{Zn}$, then $\mathrm{HOMO}$ is shifted to $\mathrm{Zn}$ atom. In general, when a metal such as $\mathrm{Zn}$ binds with many electronegative atoms present in $\mathrm{B}_{12} \mathrm{P}_{12}$ (phosphorus), then electrons from phosphorus causes the outer electron of $\mathrm{Zn}$ to be pushed out and more diffuse in nature. This results in increase in the energies of electrons present on $\mathrm{Zn}$. Therefore, HOMO resides on $\mathrm{Zn}$. If we see the frontier molecular orbital shapes of $\mathrm{Zn}$-doped $\mathrm{B}_{12} \mathrm{P}_{12}$, then $\mathrm{HOMO}$ in all geometries is located on metal which support our notion [46]. LUMO density is also shifted on metal center after adsorption of $\mathrm{Zn}$ on $\mathrm{B}_{12} \mathrm{P}_{12}$. Therefore, we can say that if LUMO energy decreases, then it shifted to metal center, and if HOMO energy increases, then it shifted 
TABle 3: The ionization potential $(I)$, electron affinity $(A)$, chemical hardness $(\eta)$, chemical potential $(\mu)$, softness $(S)$, and electrophilicity $(\omega)$ for different systems.

\begin{tabular}{|c|c|c|c|c|c|c|}
\hline Systems & $I$ & $A$ & $\eta$ & $\mu$ & $S$ & $\omega$ \\
\hline $\mathrm{Zn}$ & 6.10 & 0.55 & 2.78 & -3.33 & 0.18 & 1.99 \\
\hline $\mathrm{BP}$ & 6.83 & 3.13 & 1.06 & -4.66 & 0.47 & 6.79 \\
\hline BP- $-\mathrm{SO}_{2}$ & 6.21 & 4.20 & 1.01 & -5.21 & 0.50 & 13.46 \\
\hline Zn-BP (M1) & 6.33 & 2.99 & 1.67 & -4.66 & 0.30 & 6.51 \\
\hline $\mathrm{Zn}-\mathrm{BP}-\mathrm{SO}_{2}(\mathrm{~N} 1)$ & 5.90 & 4.75 & 0.58 & -5.33 & 0.87 & 24.52 \\
\hline Zn-BP (M2) & 6.25 & 3.16 & 1.55 & -4.71 & 0.32 & 7.16 \\
\hline $\mathrm{Zn}-\mathrm{BP}-\mathrm{SO}_{2}(\mathrm{~N} 2)$ & 6.35 & 3.84 & 1.26 & -5.10 & 0.40 & 10.32 \\
\hline Zn-BP (M3) & 5.92 & 2.99 & 1.47 & -4.46 & 0.34 & 6.77 \\
\hline $\mathrm{Zn}-\mathrm{BP}-\mathrm{SO}_{2}(\mathrm{~N} 3)$ & 5.47 & 4.18 & 0.65 & -4.83 & 0.78 & 17.95 \\
\hline $\mathrm{Zn}-\mathrm{BP}(\mathrm{M} 4)$ & 5.57 & 3.17 & 1.20 & -4.73 & 0.42 & 7.96 \\
\hline $\mathrm{Zn}-\mathrm{BP}-\mathrm{SO}_{2}(\mathrm{~N} 4)$ & 6.43 & 3.94 & 1.25 & -5.19 & 0.40 & 10.78 \\
\hline
\end{tabular}

to metal center. When we adsorbed $\mathrm{SO}_{2}$ on bare and $\mathrm{Zn}$ doped $\mathrm{B}_{12} \mathrm{P}_{12}$, then $\mathrm{HOMO}$ energies increases and $\mathrm{HOMO}$ density is shifted on $\mathrm{SO}_{2}$ and on zinc metal in all $\mathrm{SO}_{2}-$ adsorbed $\mathrm{Zn}$-doped $\mathrm{B}_{12} \mathrm{P}_{12}$ geometries. Similarly, LUMO energies decrease in all $\mathrm{SO}_{2}$-adsorbed $\mathrm{Zn}$-doped $\mathrm{B}_{12} \mathrm{P}_{12}$ geometries which causes shifting of LUMO to metal as well as $\mathrm{SO}_{2}$ as shown in Figure 5.

3.6. Partial Densities of States. Next, partial densities of states analysis is performed to visualize the change in electronic behavior of $\mathrm{B}_{12} \mathrm{P}_{12}$ upon adsorption of $\mathrm{Zn}$ as well as $\mathrm{SO}_{2}$ adsorption on bare and $\mathrm{Zn}$-doped $\mathrm{B}_{12} \mathrm{P}_{12}$. When $\mathrm{Zn}$ is adsorbed on $\mathrm{B}_{12} \mathrm{P}_{12}$ (M1, M2, M3, and M4), the HOMO has high density on cage and less density on $\mathrm{Zn}$ metal. And, LUMO has equal density on cage and metal. Similarly, when $\mathrm{SO}_{2}$ is adsorbed on $\mathrm{B}_{12} \mathrm{P}_{12}$, then $\mathrm{HOMO}$ has high density on cage and less density on $\mathrm{SO}_{2}$ and LUMO has equal densities on cage and $\mathrm{SO}_{2}$. However, we $\mathrm{SO}_{2}$ is adsorbed on $\mathrm{Zn}$-doped $\mathrm{B}_{12} \mathrm{P}_{12}(\mathrm{~N} 1, \mathrm{~N} 2, \mathrm{~N} 3$, and N4) then, HOMO has high density on cage and $\mathrm{Zn}$ metal and has less density on $\mathrm{SO}_{2}$. But LUMO has high density on $\mathrm{SO}_{2}$ and has less density on $\mathrm{B}_{12} \mathrm{P}_{12}-\mathrm{Zn}$ as shown in Figure 6.

3.7. Global Indices of Reactivity. Changes in electronic properties of $\mathrm{B}_{12} \mathrm{P}_{12}$ after adsorption of $\mathrm{Zn}$ and $\mathrm{SO}_{2}$ are analyzed in terms of global indices of reactivity (Table 3 ). Different parameters such as ionization potential $(I)$, electron affinity $(A)$, chemical potential $(\mu)$, chemical hardness $(\eta)$, softness $(s)$, and electrophilicity $(\omega)$ are discussed in Table 3. Ionization potential is the negative of energy of $\mathrm{HOMO}$ and electron affinity is negative of the energy of LUMO, according to Koopman's theorem. Pristine $\mathrm{B}_{12} \mathrm{P}_{12}$ has ionization potential of $6.83 \mathrm{eV}$ with an electron affinity of $3.13 \mathrm{eV}$. When $\mathrm{Zn}$ is placed on pure $\mathrm{B}_{12} \mathrm{P}_{12}$, then ionization potential decreases to $6.33 \mathrm{eV}$ (M1), $6.25 \mathrm{eV}$ (M2), $5.92 \mathrm{eV}$ (M3), and $5.57 \mathrm{eV}$ (M4), and electron affinity show mixed behavior to $2.99 \mathrm{eV}$ (M1), 3.16 eV (M2), $2.99 \mathrm{eV}$ (M3), and $3.17 \mathrm{eV}$ (M4) as shown in Table 3. When we adsorbed $\mathrm{SO}_{2}$ on $\mathrm{Zn}$-doped $\mathrm{B}_{12} \mathrm{P}_{12}$, then increase in ionization potential and decrease in electron affinity as compared to pure $\mathrm{B}_{12} \mathrm{P}_{12}$ is seen. Electrophilicity tells the reactivity of a molecule or compound. Adsorption of $\mathrm{Zn}$ on pure $\mathrm{B}_{12} \mathrm{P}_{12}$ increases electrophilicity. But adsorption of $\mathrm{SO}_{2}$ on pure and $\mathrm{Zn}$ doped $\mathrm{B}_{12} \mathrm{P}_{12}$ highly increases the electrophilicity as compared to $\mathrm{Zn}$-doped $\mathrm{B}_{12} \mathrm{P}_{12}$. Chemical hardness and softness is directly related to HOMO-LUMO of a compound. A compound is said to be hard in nature if it has large HOMOLUMO gap and vice versa. Adsorption of $\mathrm{Zn}$ on pure $\mathrm{B}_{12} \mathrm{P}_{12}$ makes pure $\mathrm{B}_{12} \mathrm{P}_{12}$ harder in nature. And adsorption of $\mathrm{SO}_{2}$ on pure and $\mathrm{Zn}$-doped $\mathrm{B}_{12} \mathrm{P}_{12}$ also have same effect except $\mathrm{N} 1$ and N3 where reversible is true.

\section{Conclusion}

We investigate the adsorption of $\mathrm{Zn}$ on $\mathrm{B}_{12} \mathrm{P}_{12}$. We find that $\mathrm{Zn}$ is strongly adsorbed on $\mathrm{B}_{12} \mathrm{P}_{12}$. Moreover, when we adsorbed $\mathrm{SO}_{2}$ on $\mathrm{Zn}$-doped $\mathrm{B}_{12} \mathrm{P}_{12}, \mathrm{SO}_{2}$ favorably adsorbed on $\mathrm{Zn}$-doped $\mathrm{B}_{12} \mathrm{P}_{12}$. The decreasing order of binding energy for $\mathrm{SO}_{2}$-adsorbed $\mathrm{Zn}$-doped $\mathrm{B}_{12} \mathrm{P}_{12}$ is $\mathrm{N} 3>\mathrm{N} 1>\mathrm{N} 4>\mathrm{N} 2$. Charge separation occurs when $\mathrm{Zn}$ is adsorbed on $\mathrm{B}_{12} \mathrm{P}_{12}$. But small charge separation occurs when $\mathrm{SO}_{2}$ is adsorbed on $\mathrm{Zn}$-doped $\mathrm{B}_{12} \mathrm{P}_{12}$. When $\mathrm{Zn}$ is adsorbed on $\mathrm{B}_{12} \mathrm{P}_{12}$, it causes destabilization of HOMO and stabilization of LUMO which causes of narrowing of HOMO-LUMO gap. Similar effect is seen in the case of $\mathrm{SO}_{2}$ adsorption on $\mathrm{Zn}$-doped $\mathrm{B}_{12} \mathrm{P}_{12}$. And $\mathrm{SO}_{2}$ adsorption on $\mathrm{Zn}$-doped $\mathrm{B}_{12} \mathrm{P}_{12}$ increases electrophilicity of the $\mathrm{B}_{12} \mathrm{P}_{12}$. At the end, we also performed PDOS to see the change in electronic properties of $\mathrm{B}_{12} \mathrm{P}_{12}$ after $\mathrm{Zn}$ and $\mathrm{SO}_{2}$ adsorption.

\section{Data Availability}

Electronic supplementary information is provided for the Cartesian coordinates of the optimized structures. Further data used to support the findings of this study are available from the corresponding author upon request.

\section{Conflicts of Interest}

The authors declare that they have no conflicts of interest.

\section{Acknowledgments}

The authors from Pakistan acknowledge the financial and technical support from the Shakarganj Limited Company Jhang, COMSATS University, Government College University Faisalabad, University of Okara, University of Wah, 
and Higher Education Commission (HEC) of Pakistan. The author from King Khalid University of Saudi Arabia acknowledges the Deanship of Scientific Research in King Khalid University for funding this work through Grant No. R.G.P.2/17/40.

\section{Supplementary Materials}

Cartesian coordinates of the optimized structures $\mathrm{B}_{12} \mathrm{P}_{12}$, $\mathrm{B}_{12} \mathrm{P}_{12}-\mathrm{SO}_{2}, \mathrm{~B}_{12} \mathrm{P}_{12}-\mathrm{Zn}$ (M1), $\mathrm{B}_{12} \mathrm{P}_{12}-\mathrm{Zn}$ (M2), $\mathrm{B}_{12} \mathrm{P}_{12}-\mathrm{Zn}$ (M3), $\mathrm{B}_{12} \mathrm{P}_{12}-\mathrm{Zn}$ (M4), $\mathrm{B}_{12} \mathrm{P}_{12}-\mathrm{Zn}-\mathrm{SO}_{2}$ (N1), $\mathrm{B}_{12} \mathrm{P}_{12}-\mathrm{Zn}^{-\mathrm{SO}_{2}}$ (N2), $\mathrm{B}_{12} \mathrm{P}_{12}-\mathrm{Zn}-\mathrm{SO}_{2}(\mathrm{~N} 3)$, and $\mathrm{B}_{12} \mathrm{P}_{12}-\mathrm{Zn}-\mathrm{SO}_{2}$ (N4). (Supplementary Materials)

\section{References}

[1] M. Ferroni, V. Guidi, G. Martinelli, M. Sacerdoti, P. Nelli, and G. Sberveglieri, " $\mathrm{MoO}_{3}$-based sputtered thin films for fast $\mathrm{NO}_{2}$ detection," Sensors and Actuators B: Chemical, vol. 48, no. 1-3, pp. 285-288, 1998.

[2] G. Sberveglieri, L. Depero, S. Groppelli, and P. Nelli, " $\mathrm{WO}_{3}$ sputtered thin films for $\mathrm{NO}_{\mathrm{x}}$ monitoring," Sensors and Actuators B: Chemical, vol. 26, no. 1-3, pp. 89-92, 1995.

[3] A. Gurlo, N. Bârsan, M. Ivanovskaya, U. Weimar, and W. Göpel, " $\mathrm{In}_{2} \mathrm{O}_{3}$ and $\mathrm{MoO}_{3}-\mathrm{In}_{2} \mathrm{O}_{3}$ thin film semiconductor sensors: interaction with $\mathrm{NO}_{2}$ and $\mathrm{O}_{3}$," Sensors and Actuators B: Chemical, vol. 47, no. 1-3, pp. 92-99, 1998.

[4] H. J. Cohen, R. T. Drew, J. L. Johnson, and K. V. Rajagopalan, "Molecular basis of the biological function of molybdenum: the relationship between sulfite oxidase and the acute toxicity of bisulfite and $\mathrm{SO}_{2}$," Proceedings of the National Academy of Sciences, vol. 70, no. 12, pp. 3655-3659, 1973.

[5] A. S. Lefohn and D. T. Tingey, "The co-occurrence of potentially phytotoxic concentrations of various gaseous air pollutants," Atmospheric Environment (1967), vol. 18, no. 11, pp. 2521-2526, 1984.

[6] H.-S. Wu, X.-Y. Cui, X.-F. Qin, D. L. Strout, and H. Jiao, "Boron nitride cages from $\mathrm{B}_{12} \mathrm{~N}_{12}$ to $\mathrm{B}_{36} \mathrm{~N}_{36}$ : square-hexagon alternants vs boron nitride tubes," Journal of Molecular Modeling, vol. 12, no. 5, pp. 537-542, 2006.

[7] Q.-Y. Xia, Q.-F. Lin, and W.-W. Zhao, "Theoretical study on the structural, vibrational, and thermodynamic properties of the $\left(\mathrm{Br}_{2} \mathrm{GaN}_{3}\right)_{n}(n=1-4)$ clusters," Journal of Molecular Modeling, vol. 18, no. 3, pp. 905-911, 2012.

[8] B. Yin, G. Wang, N. Sa, and Y. Huang, "Bonding analysis and stability on alternant $\mathrm{B}_{16} \mathrm{~N}_{16}$ cage and its dimers," Journal of Molecular Modeling, vol. 14, no. 9, pp. 789-795, 2008.

[9] V. Kumar, "Recent theoretical progress on electronic and structural properties of clusters: permanent electric dipoles, magnetism, novel caged structures, and their assemblies," Computational Materials Science, vol. 35, no. 3, pp. 375-381, 2006.

[10] G. Chen, Q. Peng, H. Mizuseki, and Y. Kawazoe, "Theoretical investigation of hydrogen storage ability of a carbon nanohorn," Computational Materials Science, vol. 49, no. 4, pp. S378-S382, 2010.

[11] M. Mirzaei, "Carbon doped boron phosphide nanotubes: a computational study," Journal of Molecular Modeling, vol. 17, no. 1, pp. 89-96, 2011.

[12] M. Mirzaei, "A computational NMR study of boron phosphide nanotubes," Zeitschrift für Naturforschung A, vol. 65, no. 10, pp. 844-848, 2010.
[13] M. Mirzaei and M. Giahi, "Computational studies on boron nitride and boron phosphide nanotubes: density functional calculations of boron-11 electric field gradient tensors," Physica E: Low-Dimensional Systems and Nanostructures, vol. 42, no. 5, pp. 1667-1669, 2010.

[14] D. L. Strout, "Structure and stability of boron nitrides: isomers of $\mathrm{B}_{12} \mathrm{~N}_{12}$," The Journal of Physical Chemistry A, vol. 104, no. 15 , pp. 3364-3366, 2000.

[15] R. Wang, D. Zhang, and C. Liu, “Theoretical prediction of a novel inorganic fullerene-like family of silicon-carbon materials," Chemical Physics Letters, vol. 411, no. 4-6, pp. 333-338, 2005.

[16] A. K. Kandalam, M. A. Blanco, and R. Pandey, "Theoretical study of $\mathrm{Al}_{n} \mathrm{~N}_{n}, \mathrm{Ga}_{n} \mathrm{~N}_{n}$, and $\operatorname{In}_{n} \mathrm{~N}_{n}(n=4,5,6)$ clusters," The Journal of Physical Chemistry B, vol. 106, no. 8, pp. 1945-1953, 2002.

[17] J. Beheshtian, A. A. Peyghan, and Z. Bagheri, "Quantum chemical study of fluorinated AlN nano-cage," Applied Surface Science, vol. 259, pp. 631-636, 2012.

[18] Maria, J. Iqbal, R. Ludwig, and K. Ayub, "Phosphides or nitrides for better NLO properties? A detailed comparative study of alkali metal doped nano-cages," Materials Research Bulletin, vol. 92, pp. 113-122, 2017.

[19] K. Ayub, "Binding affinity and permeation of $\mathrm{X}_{12} \mathrm{Y}_{12}$ nanoclusters for helium and neon," Journal of Molecular Liquids, vol. 244, pp. 124-134, 2017.

[20] K. Ayub, "Transportation of hydrogen atom and molecule through $\mathrm{X}_{12} \mathrm{Y}_{12}$ nano-cages," International Journal of $\mathrm{Hy}$ drogen Energy, vol. 42, no. 16, pp. 11439-11451, 2017.

[21] K. Ayub, "Are phosphide nano-cages better than nitride nano-cages? A kinetic, thermodynamic and non-linear optical properties study of alkali metal encapsulated $\mathrm{X}_{12} \mathrm{Y}_{12}$ nanocages," Journal of Materials Chemistry C, vol. 4, no. 46, pp. 10919-10934, 2016.

[22] S. Munsif and K. Ayub, "Permeability and storage ability of inorganic $\mathrm{X}_{12} \mathrm{Y}_{12}$ fullerenes for lithium atom and ion," Chemical Physics Letters, vol. 698, pp. 51-59, 2018.

[23] A. Soltani, M. T. Baei, M. R. Taghartapeh, E. T. Lemeski, and S. Shojaee, "Phenol interaction with different nano-cages with and without an electric field: a DFT study," Structural Chemistry, vol. 26, no. 3, pp. 685-693, 2015.

[24] A. Soltani, S. G. Raz, M. R. Taghartapeh, A. V. Moradi, and R. Z. Mehrabian, "Ab initio study of the $\mathrm{NO}_{2}$ and $\mathrm{SO}_{2}$ adsorption on $\mathrm{Al}_{12} \mathrm{~N}_{12}$ nano-cage sensitized with gallium and magnesium," Computational Materials Science, vol. 79, pp. 795-803, 2013.

[25] A. Ahmadi Peyghan, M. Pashangpour, Z. Bagheri, and M. Kamfiroozi, "Energetic, structural, and electronic properties of hydrogenated $\mathrm{Al}_{12} \mathrm{P}_{12}$ nanocluster," Physica E: LowDimensional Systems and Nanostructures, vol. 44, no. 7-8, pp. 1436-1440, 2012.

[26] A. S. Rad and K. Ayub, "Ni adsorption on $\mathrm{Al}_{12} \mathrm{P}_{12}$ nano-cage: a DFT study," Journal of Alloys and Compounds, vol. 678, pp. 317-324, 2016.

[27] R. Padash, A. Sobhani-Nasab, M. Rahimi-Nasrabadi et al., "Is it possible to use $\mathrm{X}_{12} \mathrm{Y}_{12}(\mathrm{X}=\mathrm{Al}, \mathrm{B}$, and $\mathrm{Y}=\mathrm{N}, \mathrm{P})$ nanocages for drug-delivery systems? A DFT study on the adsorption property of 4-aminopyridine drug," Applied Physics A, vol. 124, no. 9, p. 582, 2018.

[28] A. S. Rad, S. M. Aghaei, V. Poralijan, M. Peyravi, and M. Mirzaei, "Application of pristine and Ni-decorated $\mathrm{B}_{12} \mathrm{P}_{12}$ nano-clusters as superior media for acetylene and ethylene adsorption: DFT calculations," Computational and Theoretical Chemistry, vol. 1109, pp. 1-9, 2017. 
[29] A. S. Rad, A. Mirabi, M. Peyravi, and M. Mirzaei, "Nickeldecorated $\mathrm{B}_{12} \mathrm{P}_{12}$ nanoclusters as a strong adsorbent for $\mathrm{SO}_{2}$ adsorption: quantum chemical calculations," Canadian Journal of Physics, vol. 95, no. 10, pp. 958-962, 2017.

[30] S. Munsif, Maria, S. Khan et al., "Remarkable nonlinear optical response of alkali metal doped aluminum phosphide and boron phosphide nanoclusters," Journal of Molecular Liquids, vol. 271, pp. 51-64, 2018.

[31] A. S. Rad and K. Ayub, "How can nickel decoration affect $\mathrm{H}_{2}$ adsorption on $\mathrm{B}_{12} \mathrm{P}_{12}$ nano-heterostructures?" Journal of Molecular Liquids, vol. 255, pp. 168-175, 2018.

[32] E. Jenne, Adsorption of Metals by Geomedia: Variables, Mechanisms, and Model Applications, Elsevier, Amsterdam, Netherlands, 1998.

[33] J. L. Li, Z. S. Hu, and G. W. Yang, "High-capacity hydrogen storage of magnesium-decorated boron fullerene," Chemical Physics, vol. 392, no. 1, pp. 16-20, 2012.

[34] K. Sato and H. Katayama-Yoshida, "Material design of GaNbased ferromagnetic diluted magnetic semiconductors," Japanese Journal of Applied Physics, vol. 40, no. 5, pp. L485-L487, 2001.

[35] J. E. Medvedeva, A. J. Freeman, X. Y. Cui, C. Stampfl, and N. Newman, "Half-metallicity and efficient spin injection in AlN/GaN:Cr (0001) heterostructure," Physical Review Letters, vol. 94, no. 14, Article ID 146602, 2005.

[36] Q. Wang, A. K. Kandalam, Q. Sun, and P. Jena, "Ferromagnetism in $\mathrm{Al}_{1-\mathrm{x}} \mathrm{Cr}_{\mathrm{x}} \mathrm{N}$ thin films by density functional calculations," Physical Review B, vol. 73, no. 11, Article ID 115411, 2006.

[37] Y. Zhang, X. Zheng, S. Zhang, S. Huang, P. Wang, and $\mathrm{H}$. Tian, "Bare and $\mathrm{Ni}$ decorated $\mathrm{Al}_{12} \mathrm{~N}_{12}$ cage for hydrogen storage: a first-principles study," International Journal of Hydrogen Energy, vol. 37, no. 17, pp. 12411-12419, 2012.

[38] D. Pan, J. K. Jian, Y. F. Sun, and R. Wu, "Structure and magnetic characteristics of Si-doped AlN films," Journal of Alloys and Compounds, vol. 519, pp. 41-46, 2012.

[39] X. Y. Cui, D. Fernandez-Hevia, B. Delley, A. J. Freeman, and C. Stampfl, "Embedded clustering in Cr-doped AlN: evidence for general behavior in dilute magnetic III-nitride semiconductors," Journal of Applied Physics, vol. 101, no. 10, p. 103917, 2007.

[40] A. V. Marenich, C. J. Cramer, D. G. Truhlar et al., "Practical computation of electronic excitation in solution: vertical excitation model," Chemical Science, vol. 2, no. 11, p. 2143, 2011.

[41] R. G. Parr, L. V. Szentpály, and S. Liu, "Electrophilicity index," Journal of the American Chemical Society, vol. 121, no. 9, pp. 1922-1924, 1999.

[42] R. G. Pearson, "The transition metal-carbon monoxide bond," Inorganic Chemistry, vol. 23, no. 26, pp. 4675-4679, 1984.

[43] T. Lu and F. Chen, "Multiwfn: a multifunctional wavefunction analyzer," Journal of Computational Chemistry, vol. 33, no. 5, pp. 580-592, 2012.

[44] S. S. Li, "Scattering mechanisms and carrier mobilities in semiconductors," in Semiconductor Physical Electronics, pp. 211-245, Springer New York, New York, NY, USA, 1993.

[45] C. A. Mead and W. G. Spitzer, "Fermi level position at semiconductor surfaces," Physical Review Letters, vol. 10, no. 11, pp. 471-472, 1963.

[46] A. S. Rad and K. Ayub, "Adsorption of pyrrole on $\mathrm{Al}_{12} \mathrm{~N}_{12}$, $\mathrm{Al}_{12} \mathrm{P}_{12}, \mathrm{~B}_{12} \mathrm{~N}_{12}$, and $\mathrm{B}_{12} \mathrm{P}_{12}$ fullerene-like nano-cages; a first principles study," Vacuum, vol. 131, pp. 135-141, 2016. 